\title{
POSTSCRIPT: REFLECTIONS ON SUPERALLOY 718
}

\author{
Edward A. Loria \\ Metallurgical Consultant \\ 1828 Taper Drive \\ Pittsburgh, Pennsylvania 15241
}

The four Symposia have reviewed worldwide developments on the theory, technology and application of Superalloys 718, 625, 706 and Derivatives from 1989 to 1997. The attractive balance of properties offered by these unique alloys derives from an advanced understanding of optimizing microstructure through the controlled interaction between melting and processing. By returning to our initial consideration, Alloy 718 , this postscript reflects on the changes in melting and processing which have taken place that are deemed most important in this respect.

\section{Clean Melt Practice}

The component life of an aircraft engine depends upon two important material parameters: The maximum allowable defect size and the crack growth rate under the operating conditions. Hence, instead of design for a static property, such as ultimate tensile strength, design is now based on a dynamic property, such as low cycle fatigue, creep or stress rupture. Improved 718 and component life required advances in melting techniques to insure product reliability through control of defects such as impurities (inclusions) and solidification flaws (freckles, white spots and carbide stringers).

The major thrust has been to reduce defects through clean melt practice. This meant not only evaluating the existing practices but developing the best combination since each of them

Trends (Rank) Of Superalloy Melt Practices

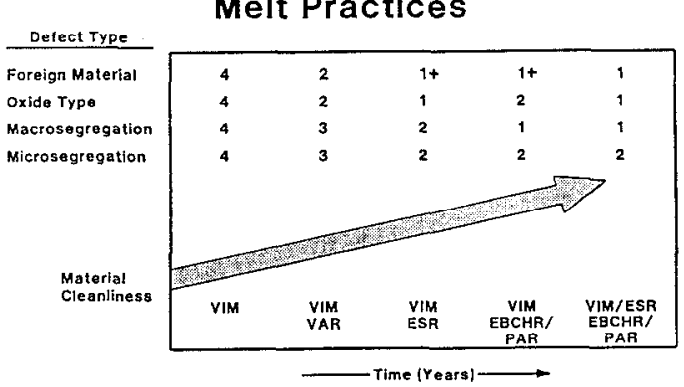

DIRECT AGED IN7 18

VIM-VAR VS. VIM-ESR-VAR

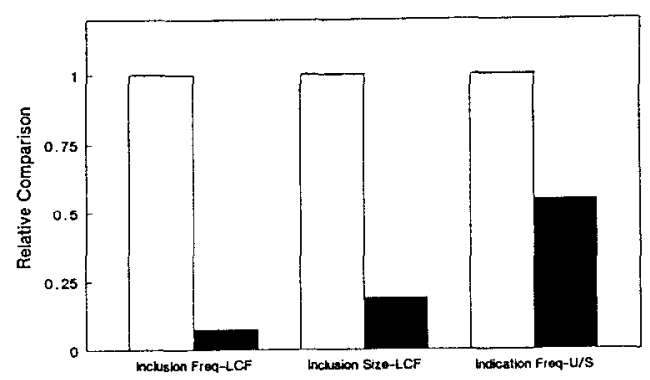

Figure 1. Rank (trend) of superalloy melt practices with respect to defect type and material cleanliness.

Figure 2. Relative comparison of VIM-VAR vs. VIM-ESR-VAR on inclusion size and frequency in LCF specimens of direct aged 718 (inclusions $=$ oxides, nitrides and carbonitrides). 
have limitations that produce melt related defects. The trend of improvement in material cleanliness with respect to defect type is depicted in Figure 1. Refining for cleanliness has now reached the stage where advanced remelting processes are being considered but the cost/benefit trade-off for Alloy 718 is being achieved by the VIM-ESR-VAR triple melt process.

Improved tensile and LCF properties have required billet and forging suppliers to produce Alloy 718 disks with smaller and smaller grain sizes. As grain size is reduced, LCF initiation sites change from primarily grain to inherent inclusions (oxides, nitridesand carbonitrides). Thus, for a fine grain material like DA718, the minimum LCF life is controlled by inclusions. The need for more uniform LCF properties in DA718 was met by the introduction of the triple melt process which inserted ESR between VIM and VAR and dramatically reduced the oxide size and distribution (1), per Figure 2. The frequency of inclusions in LCF specimen failure has been reduced by $90 \%$, the average inclusion size reduced by $80 \%$ and the number of rejectable ultrasonic inclusions in billets has been cut in half (1). These dramatic improvements have resulted in the use of several million pounds of triple melted DA718 by GE Aircraft Engines.

Low cycle fatigue and cyclic crack preparation at $550-650^{\circ} \mathrm{C}$ are dominant damage mechanism for turbine disks. Life prediction is based on the occurrence of crack initiation from inclusirasand oxygen penetration. After a few cycles, crack initiation occurs from surface and subsurface inchusions and then crack propagation proceeds via the size and statistical distribution of inclusions coupled with oxygen penetration. Variations in fatigue crack growth rates are mainly related to strong intergranular effects and correspond to a transition from transgranular fracture at high frequency to intergranular fracture at low frequency (2). At $650^{\circ} \mathrm{C}$, the fatigue crack growth rate in air tends to be essentially time dependent at low frequency, per Figure 3 . The effect of oxygen partial pressure on oxidation-assisted crack growth (intergranuler fracture) is shown in Figure 4, and has been correlated with the composition of the oxide films offering surface protection, as well as the build-up of spinel oxides shead of the crack tip (2).

Alloy cleanliness has been upgraded through control of raw materials and processes for improved electrode preparation and then tighter control of remelting parameters. Improved cleanliness also promoted VAR stability and larger 30 inch diameter ingots have been produced
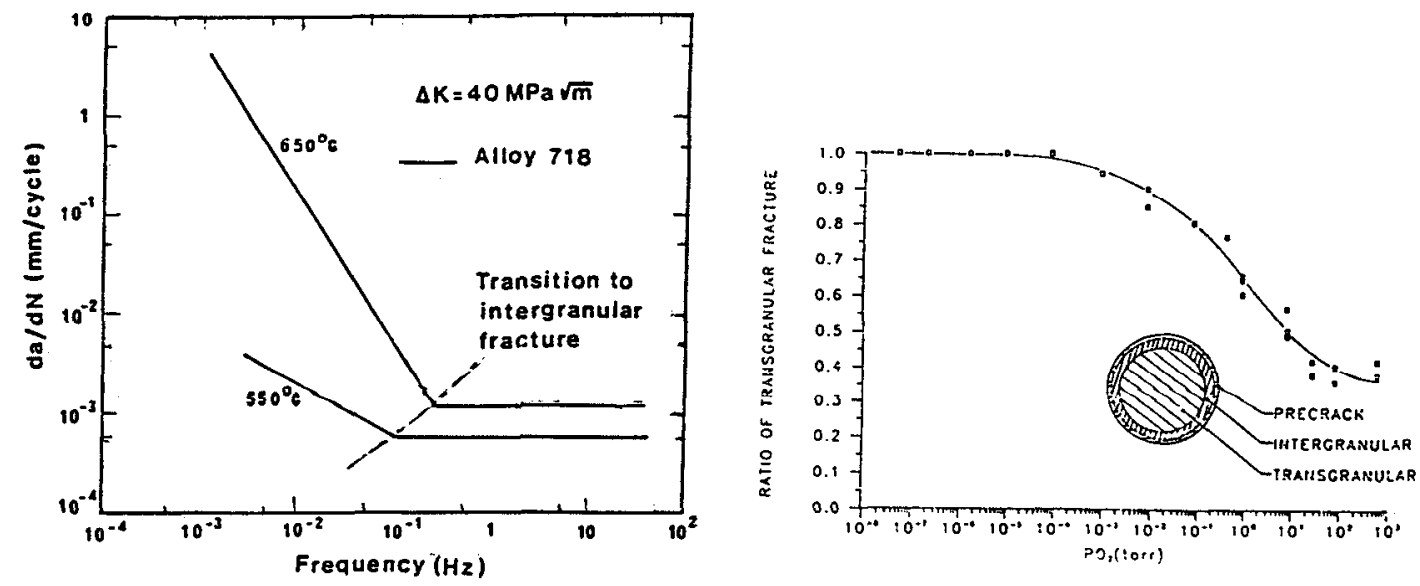

Figure 3. Variation of fatigue crack growth rate with frequency in Alloy 718 . The results for the transition to intergranular fracture are taken from several studies.

Figure 4. Influence of the partial oxygen pressure on intergranular fracture in Alloy 718. 
with homogeneity comparable to that in smaller 20 inch diameter ingots. Improved cleanliness permits more aggressive hot working techniques. Because cleaner metal is less prone to cracking, much larger work reductions have been possible. This capability, coupled with lower finishforging temperatures, produced finer grain product. For example, 14 in. diameter 718 billet can be produced with an ASTM6 grain size, permitting ultrasonic inspection to $50 \%$ of 0.03 inch defect levels (3).

Improvements in grain size and cleanliness also permit tight ultrasonic inspection limits. Ten years ago, a 0.08 inch indication was a common rejection standard. Today, a reading of 0.03 to 0.05 inch is a common inspection threshold (3). Thus, designers may assume a much smaller flaw size when establishing design stresses. As a result, Alloy 718 components can be made lighter in weight or operate under higher stress conditions.

\section{Processing Aspects}

The cornerstone in making a successful forging has to be ingot uniformity (homogeneity and cleanliness) in order to achieve consistency and reproducibility in the conversion of the ingot to forging billet. Commercial processing of Alloy 718 can lead to a heterogeneous grain structure which is carried through the final forging and heat treatment. The value of having a uniform and fine grain size is enormous since this material is then used as feedstock for the production of turbine disks and other components.

The progress in utilizing compression testing of small specimens cut from billet and bar stock, in order to optimize processing conditions of temperature and strain rate, has been covered in our Symposia. One distinctive study on Alloy 718 (4) employed compression testing of specimens cut from a 12 inch diameter ingot and defined the proper TMP conditions that produced substantial grain refinement. The recrystallization- temperature-time surface map under dynamic and static conditions shown in Figure 5 and the three dimensional power dissipation map shown in Figure 6 illustrate the development of compression testing as a means of quantifying hot deformation behavior and microstructure.
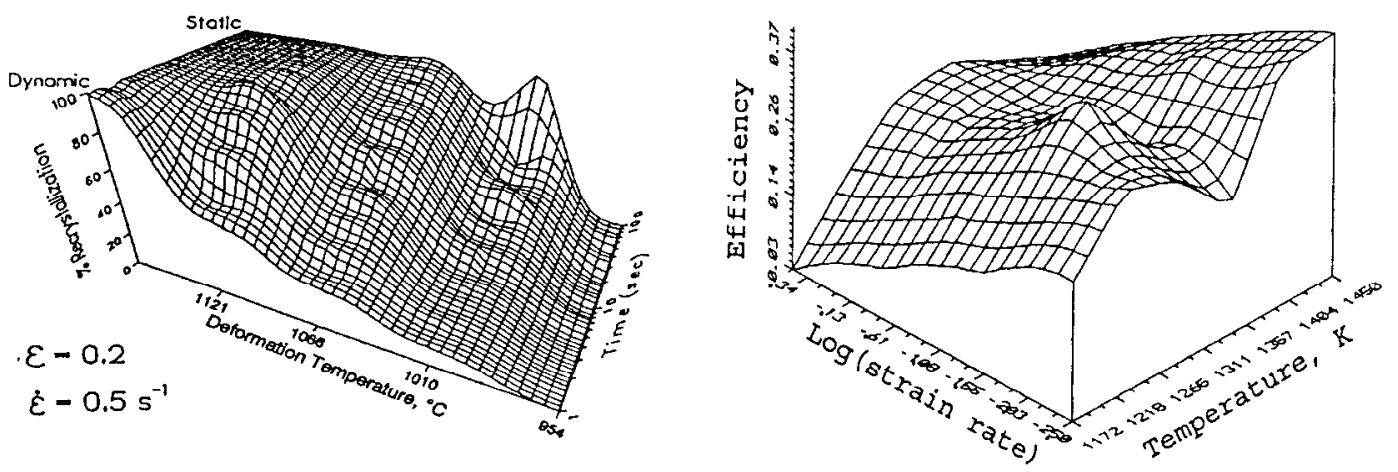

Figure 5. Recrystallization-temperature-time surface map for Alloy 718 under dynamic and static conditions.

Figure 6. Three-dimensional power dissipation map for Alloy 718 at a strain of 0.5 
The usage of larger forging presses has been a major factor in the improvement of Alloy 718 billet and bar quality. Various forging processes are now combined in this endeavor. For example, a 3000 ton press is used to break up cast ingot structures. Material is then transferred to a large rotary forge where many large reductions can be made without reheating the product. Efficiency is very high compared with straight-through forging, and finer grain sizes can be achieved. A large rotary forge can also convert ingot directly to billet and bar with great efficiency if coarser grain sizes are permissible. Through better homogeneity, greater cleanliness, enhanced workability and improved reliability (via tighter inspection limits), larger diameter product has become increasingly available.

Turbine disks are designed for high yield strength and crack resistance. Their quality is maintained through careful control of alloy cleanliness to eliminate inclusions or clusters of precipitate particles that can constitute a critical defect. One remaining challenge to the modeling of disks is accounting for the possible presence of defects which are too dilute to be characterized by metallographic or NDT techniques. Attention must be focused on control of the entire processing cycle with emphasis on modeling the critical melting processes.

Finally, redesign of Alloy 718 has been considered in order to provide microstructural and mechanical stability at and beyond $650^{\circ} \mathrm{C}$. At this point, there are strong indications that minor modifications in composition produce precipitate strengthening with appropriate (final) heat treatment. However, the extent of improvement has not been translated to a section size corresponding to a commercial product because only small quantities have been produced. This could be ascertained by the procedure (5) of solution treating and quenching a tensile bar, under well-controlled conditions so that the cooling rate is known and then repeating this procedure to obtain different cooling rates in three more bars and then developing the relationship with tensile properties (and section size) shown in Figure 7.

An alternate method that requires only one test bar is the Jominy test which determines the hardenability or change of microstructure of steel. The writer (6) has used the wide range of cooling rate in a Jominy bar, per Figure 8, to detect sensitization in Type 304 stainless steel which is a change in microstructure with a change in cooling rate (section size) from the solution
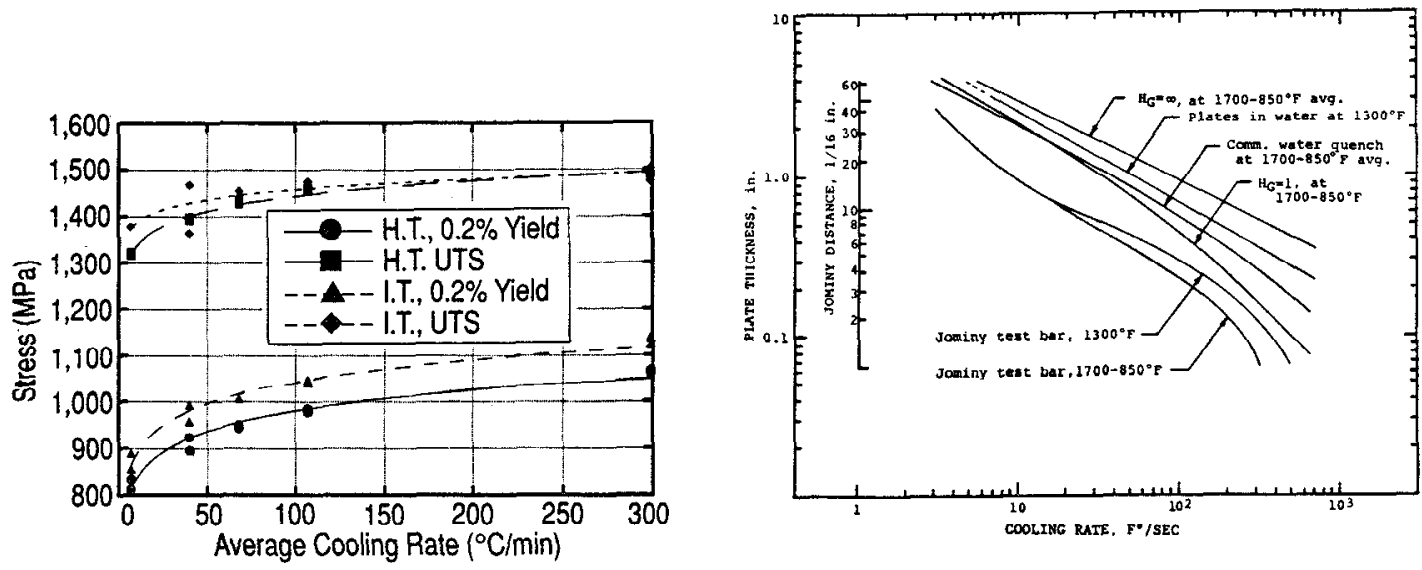

Figure 7. The relationship between cooling rates and mechanical properties.

Figure 8. Equivalent cooling rates in Jominy end quench test bars and mid-thickness of waterquenched plates at $1700-850^{\circ} \mathrm{F}$ avg. or at $1300^{\circ} \mathrm{F}$. 
treatment. After a Jominy bar of modified 718 is quenched from the solution temperature and given the appropriate aging treatment, the cross section can be examined at two or three distances from the quenched end to ascertain if the desired precipitate morphology is still maintained for the corresponding plate thickness or bar diameter. Thus, it can be determined if the compact $\gamma^{\prime} / \gamma^{\prime \prime}$ precipitate found in small sections can be reproduced with increasing section size. Also, hardness at the chosen distance from the quenched end (corresponding to section size) can be obtained, as well as its stability after a certain time exposure at 650 to $750^{\circ} \mathrm{C}$.

\section{Closure}

The four volumes cover a progression of knowledge from 1989 to 1997 on our special emphasis superalloys. Some of it was applied research designed to help cure or mitigate a problem in production or application directly. Some of it was basic research, designed only to understand how these materials work--but with ultimately practical benefits, serendipitous results. Alloy 718 illustrates this understanding through the melting and processing developments that have eliminated costly trials and errors. The low alloying and processing costs, combined with ease of fabrication and attractive final properties, make this superalloy very cost-effective and maintain its foremost position in terms of production and usage to this day.

\section{$\underline{\text { References }}$}

1. R. D. Kissinger, Bakish Conference on Electron Beam Melting and Refining, Reno, Nevada October 1991.

2. A. Pineau , Proceedings of Symposium on High Temperature Materials for Power Engineering 1990, CEM Liege, Kluever Academic Publishers (1990), pp. 913-933.

3. K.P. Rohrbach, Advanced Materials \& Processing, ASM (October 1995), pp. 37-40.

4. C. I. Garcia, D. E. Camus, E.A. Loria and A.J. DeArdo, Proceedings of Symposium on Superalloy 718, 625 and Various Derivatives 1991, TMS (1991), pp. 147-160, also Proceedings of Symposium on Superalloys 1992, TMS (1992), pp. 527-536.

5. H. E. Delgado, R. I. Ramakrishnan and T. E. Howson, JOM, TMS (September 1994), pp. 2123.

6. E. A. Loria, J. Metals, TMS (June 1979), pp. 137-146 and (December 1979), pp.163-167, also Materials Science \& Engineering, 76 (1985), pp. 159-172. 